\title{
Implementation and application of a multiplex assay to detect malaria-specific antibodies: a promising tool for assessing malaria transmission in Southeast Asian pre-elimination areas
}

\author{
Karen Kerkhof ${ }^{1,2^{*}} \mathbb{D}$, Lydie Canier ${ }^{3}$, Saorin Kim³ ${ }^{3}$, Somony Heng ${ }^{4}$, Tho Sochantha ${ }^{4}$, Siv Sovannaroth ${ }^{4}$, \\ Inès Vigan-Womas ${ }^{5}$, Marc Coosemans ${ }^{1,2}$, Vincent Sluydts ${ }^{1,6}$, Didier Ménard ${ }^{3}$ and Lies Durnez ${ }^{1 *}$
}

\begin{abstract}
Background: Epidemiological surveillance is a key activity in malaria control and elimination in low-transmission and pre-elimination settings. Hence, sensitive tools for estimating malaria force of infection are crucial. Serological markers might provide additional information in estimating force of infection in low-endemic areas along with classical parasite detection methods. Serological markers can be used to estimate recent, past or present malaria exposure, depending on the used markers and their half-life.

Methods: An assay based on 14 Plasmodium-specific peptides, one peptide specific for Anopheles gambiae saliva protein and five Plasmodium-specific recombinant proteins was developed for the MAGPIX system, assessed for its performance, and applied on blood spots from 2000 individuals collected in the Ratanakiri Province, Cambodia.

Results: A significant correlation for the use of 1000 and 2000 beads/antigen/well as well as for the monoplex versus multiplex assay was observed for all antigens $(p<0.05)$. For the majority of antigens, antigen-coupled beads were stable for at least 2 months. The assay was very reproducible with limited intercoupling, interplate and intraplate variability (mean RSD $<15 \%$ ). Estimating seroconversion and seroreversion per antigen using reversible catalytic models and models allowing two seroconversion rates showed higher seroconversion rates in adults.

Conclusion: The multiplex bead-based immunoassay was successfully implemented and analysis of field blood samples shows that changes detected in force of malaria infection vary according to the serological markers used. Multivariate analysis of the antibody responses and insights into the half-life of antibodies are crucial for improving the interpretation of these results and for identifying the most useful serological markers of past and recent malaria infection.
\end{abstract}

Keywords: Malaria, Serological markers, Multiplex immunoassay, Cambodia

\section{Background}

Globally an estimated 3.4 billion people in 107 malariaendemic countries are at risk of malaria, of which 1.2

\footnotetext{
*Correspondence: kkerkhof@itg.be; Idurnez@itg.be

1 Department of Biomedical Sciences, Institute of Tropical Medicine,

Antwerp, Belgium

Full list of author information is available at the end of the article
}

billion at high risk [1] live mostly in the African region $(47 \%)$ and the Southeast Asian region (37\%). To control and eliminate malaria, WHO recommends a multi-pronged strategy, which includes vector control interventions, preventive therapy, diagnostic testing, treatment with quality-assured artemisinin-based combination therapy (ACT) as well as strong epidemiological surveillance [1]. Through upscaling of several elements of 
this strategy, many countries are on the verge of reaching pre-elimination. The low transmission rates in these areas pose considerable challenges for epidemiological surveillance [2], hindering the evaluation of new (vector) control tools necessary to reach elimination [1].

Detection of malaria-infected persons by microscopy, rapid diagnostic tests (RDTs) and even PCR lacks sensitivity because of low numbers of positive samples [3], representing a formidable logistical challenge due to the very big sample sizes required in surveillance and evaluation surveys. While parasite-prevalence (measured by microscopy, RDTs or PCR) provides a snapshot of the exposure to malaria, the use of serological markers can provide a picture of the malaria transmission over a prolonged period $[3,4]$. Serology is based on the detection of antibodies (Abs) against antigens (Ags) of malaria parasites, which offers an advantage as anti-Plasmodium Abs can persist for months after infection. Therefore, these Abs have been suggested as indicators of malaria transmission [5-8], and are believed to be a better approach to determine past, recent and present malaria exposure [9]. Previous studies performed in low transmission settings, such as Cambodia, also suggest that serological assays are promising for indicating malaria transmission [3, 10-12].

Since the 1960 s, serological markers detected by indirect immunofluorescence antibody tests (IFAT) were used to assess malaria transmission intensity and reductions in transmission [13]. This has proven to be a reliable and useful serological test for malaria in epidemiological surveys $[5,6,14]$. However, variation in source of Ags and the subjectivity of IFAT has led to this method falling out of favour [4]. Standardized tests based on recombinant Ags used in an enzyme-linked immunosorbent assay (ELISA) were therefore developed [4, 7-9]. However, an ELISA can only assess one marker at a time, making it labour intensive and time consuming when interested in multiple $\mathrm{Ab}$ responses. In the context of malaria elimination it will become essential to take into account individual variations in $\mathrm{Ab}$ responses, the occurrence of multiple malaria parasites [15], as well as to increase the probability of measuring changes in $\mathrm{Ab}$ responses by combining different markers. Recently, several multiplex assays that were testing for different serological markers in the same blood sample, were developed by different research teams based on the Luminex technology [15-18].

In this context, the general objective of this study was to implement an existing assay based on the Luminex technology for detection of Abs against malaria parasites in blood samples from Ratanakiri Province, Cambodia. This is the first and most extensive multiplex assay in malaria serology executed in the Southeast Asian region, including 20 Ags (recombinant proteins and peptides) directed against different specific malaria parasites.
Furthermore, this study includes a detailed analysis on the stability of coated beads over time and the reproducibility of the beads coupling and immunoassay.

\section{Methods \\ Samples}

A positive control for the assay was prepared by pooling sera from four Plasmodium falciparum- and two Plasmodium vivax-infected patients from Ratanakiri Province in Cambodia. Dilutions of this positive control pool were prepared at 1:100, 1:400 and 1:1600 in PBS-CR (phosphate buffered saline, Charles River Laboratories Inc, MA, USA). These dilutions were used to assess the performance of the assay and as positive control samples in the immunoassay applied on field blood samples. The latter were collected in Ratanakiri Province, Cambodia, on filter papers through finger prick, during April-May 2012 (baseline survey of the MalaResT project, NCT01663831, that aims to evaluate the use of topical repellents, in addition to long-lasting insecticidal nets, on malaria prevalence and incidence [19, 20]). Out of 5392 blood spot samples collected, 2000 were randomly chosen for the immunoassay and after quality control, 1931 samples were used for data analysis. Blood spot filter papers were prepared by punching two discs of 4-mm diameter, and eluted overnight in $160 \mu \mathrm{L}$ of PBS-TBN (dilution 1:40, PBS-1 \% BSA-0.15 \% Tween, pH 7.4, Sigma-Aldrich). Just before use in the immunoassay, the eluted samples were further diluted to 1:200 in PBS-CR.

\section{Antigens}

Selection of peptides specific for $P$. falciparum representing different life stages of the parasite was based on the work of Ambrosino et al. [5]. Additionally, peptides specific for Anopheles gambiae saliva protein [5], P. vivax and Plasmodium malariae were included in the assay, as well as specific recombinant proteins for $P$. falciparum and $P$. vivax (Table 1 ). All peptides were chemically synthesized with an added $\mathrm{N}$-terminal cysteine residue and bovine serum albumin (BSA) (Table 1) [5] by GeneCust Europe (Dudelange, Luxembourg). The recombinant proteins were synthesized as described in Table 1 . This study consisted of two phases (performance assessment of the assay, and application to field samples; Fig. 1). For practical reasons, some steps carried out during the performance assessment used a slightly different Ag set (Fig. 1).

\section{Covalent coupling of antigens to the beads/microspheres}

Covalent coupling of paramagnetic beads (MagPlex microspheres, Luminex Corp, Austin, TX, USA) was carried out as described by Ambrosino et al. [5] and the Luminex Corp [21, 22]. Each Ag was coupled at a concentration of $4 \mu \mathrm{g} \mathrm{Ag} / 10^{6}$ beads to $1 \times 10^{6}$ beads/beadset 
Table 1 Overview of the antigens (peptides and recombinant proteins) used in this study

\begin{tabular}{|c|c|c|c|c|c|c|}
\hline Antigens & $\begin{array}{l}\text { Sequence (N-terminal } \\
\text { to C-terminal) }\end{array}$ & $\mathrm{g} / \mathrm{mol}$ & Life-cycle stages & Plasmodium species & $\begin{array}{l}\text { Peptide or recombinant } \\
\text { protein }\end{array}$ & References \\
\hline CSP & $\begin{array}{l}\text { NANPNANPNANPNANPNVDP- } \\
\text { NVDPC }\end{array}$ & -2557.67 & Sporozoite & P. falciparum & Peptide & {$[5]$} \\
\hline Pfl3 & $\begin{array}{l}\text { C-terminal His-tag produced } \\
\text { in E. coli }\end{array}$ & & Sporozoite & P. falciparum & Recombinant protein & {$[45,46]$} \\
\hline STARP-R & STDNNNTKTISTDNNNTKTIC & 2299.42 & Sporozoite and liver stage & P. falciparum & Peptide & {$[5,47]$} \\
\hline SALSA 1 & $\begin{array}{l}\text { SAEKKDEKEASEQGEESHKKEN- } \\
\text { SQESAC }\end{array}$ & 3123.24 & Sporozoite and liver stage & P. falciparum & Peptide & {$[5,47]$} \\
\hline SALSA 2 & $\begin{array}{l}\text { NGKDDVKEEKKTNEKKDDGKT- } \\
\text { DKVQEKVLEKSPKC }\end{array}$ & 4019.52 & Sporozoite and liver stage & P. falciparum & Peptide & {$[5,47$} \\
\hline SR11.1 & EEVVEELIEEVIPEELVLC & 2213.5 & Sporozoite and liver stage & P. falciparum & Peptide & {$[5,47]$} \\
\hline LSA1-41 & $\begin{array}{l}\text { LAKEKLQEQQSDLEQER- } \\
\text { LAKEKLQEQQSDLEQER- } \\
\text { LAKEKEKLQC }\end{array}$ & 5297.97 & Liver stage & P. falciparum & Peptide & {$[5,6,48]$} \\
\hline LSA1-J & $\begin{array}{l}\text { ERRAKEKLQEQQSDLEQRKADT- } \\
\quad \text { KKC }\end{array}$ & -3046.43 & Liver stage & P.falciparum & Peptide & {$[5,47,48]$} \\
\hline LSA3-NR2 & $\begin{array}{l}\text { VLEESQVNDDIFNSLVKS- } \\
\text { VQQEQQHNVC }\end{array}$ & 3230.53 & Liver stage & P.falciparum & Peptide & {$[5,47]$} \\
\hline LSA3-RE & $\begin{array}{l}\text { VESVAPSVEESVAPSVEESVAEN- } \\
\text { VEESVC }\end{array}$ & 2991.2 & Liver stage & P. falciparum & Peptide & {$[5,47]$} \\
\hline PfMSPI-19 & $\begin{array}{l}\text { Glutathione S-transferase } \\
\text { (GST) fusion protein. C-ter- } \\
\text { minal expressed in E. coli }\end{array}$ & & Merozoite & P. falciparum & Recombinant protein & {$[4,24]$} \\
\hline GLURP & EDKNEKGQHEIVEVEEILC & 2241.47 & Trophozoite & P. falciparum & Peptide & {$[5,47,49]$} \\
\hline GLURP-P3 & EPLEPFPTQIHKDYKC & 1945.23 & Trophozoite & P. falciparum & Peptide & {$[5,47,50]$} \\
\hline PfGLURP-R2 & C-terminal produced in E. coli & & Trophozoite & P. falciparum & Recombinant protein & {$[49]$} \\
\hline Pvlike CSP & $\begin{array}{l}\text { APGANQEGGAAAPGANQEG- } \\
\text { GAAAPGANQEGGAAC }\end{array}$ & 2892.99 & Sporozoite & P. vivax & Peptide & {$[47]$} \\
\hline PVVK210 CSP & $\begin{array}{l}\text { DGQPAGDRAAGQPAG- } \\
\text { DRADGQPAGDRADGQPAGC }\end{array}$ & 3206.3 & Sporozoite & P. vivax & Peptide & {$[47,51,52]$} \\
\hline PVVK247 CSP & $\begin{array}{l}\text { ANGAGNQPGANGAGNQP- } \\
\text { GANGAGNQPGANGAGNC }\end{array}$ & 2905.95 & Sporozoite & P. vivax & Peptide & {$[47,51,52]$} \\
\hline PvCSP-chimera & $\begin{array}{l}\text { Soluble His-tag protein } \\
\text { expressed in wheat-germ } \\
\text { cell free expression system }\end{array}$ & & Sporozoite & P. vivax & Recombinant protein & {$[51,52]$} \\
\hline PvAMAI & & & Merozoite & P. vivax & Recombinant protein & {$[53,54]$} \\
\hline PvDBP & & & Merozoite & P. vivax & Recombinant protein & {$[55]$} \\
\hline PVMSPI-19 & $\begin{array}{l}\text { C-terminal produced in the } \\
\text { baculovirus expression } \\
\text { system }\end{array}$ & & Merozoite & P. vivax & Recombinant protein & {$[4,16,24]$} \\
\hline PmCSP & $\begin{array}{l}\text { GNAAGNAAGNDAGNAA- } \\
\text { GNAAGNAAGNAAGNAAC }\end{array}$ & 2358.37 & Sporozoite & P. malariae & Peptide & {$[47]$} \\
\hline SALIV 1 & $\begin{array}{l}\text { EKVWVDRDNVYCGHLDC- } \\
\text { TRVATFC }\end{array}$ & 2830.22 & Salivary gland proteins & An. gambiae & Peptide & {$[5,56]$} \\
\hline SALIV 2 & $\begin{array}{l}\text { ATFKGERFCTLCDTRHFCECK- } \\
\text { ETREPLC }\end{array}$ & 3324.84 & Salivary gland proteins & An.gambiae & Peptide & {$[5,56]$} \\
\hline
\end{tabular}

Ags are organized according to the Plasmodium species and the life-cycle stages in the human host

for performance assessment (Fig. 1). When applying the assay on blood samples from Ratanakiri, all Ags were coupled twice to $5 \times 10^{6}$ beads/beadset, and mixed for homogenous coupling. BSA (Sigma-Aldrich, St Louis, USA) was coupled to an additional set of beads to serve as a background control $[5,23]$.

\section{Bead-based immunoassay}

The immunoassay was carried out as described previously [5, 17, 22, 24, 25], with minor adjustments. A microsphere working mixture was prepared in PBS$\mathrm{CR}$, with a concentration of 1000 beads/Ag/well (except in the experiment to assess the difference between a 


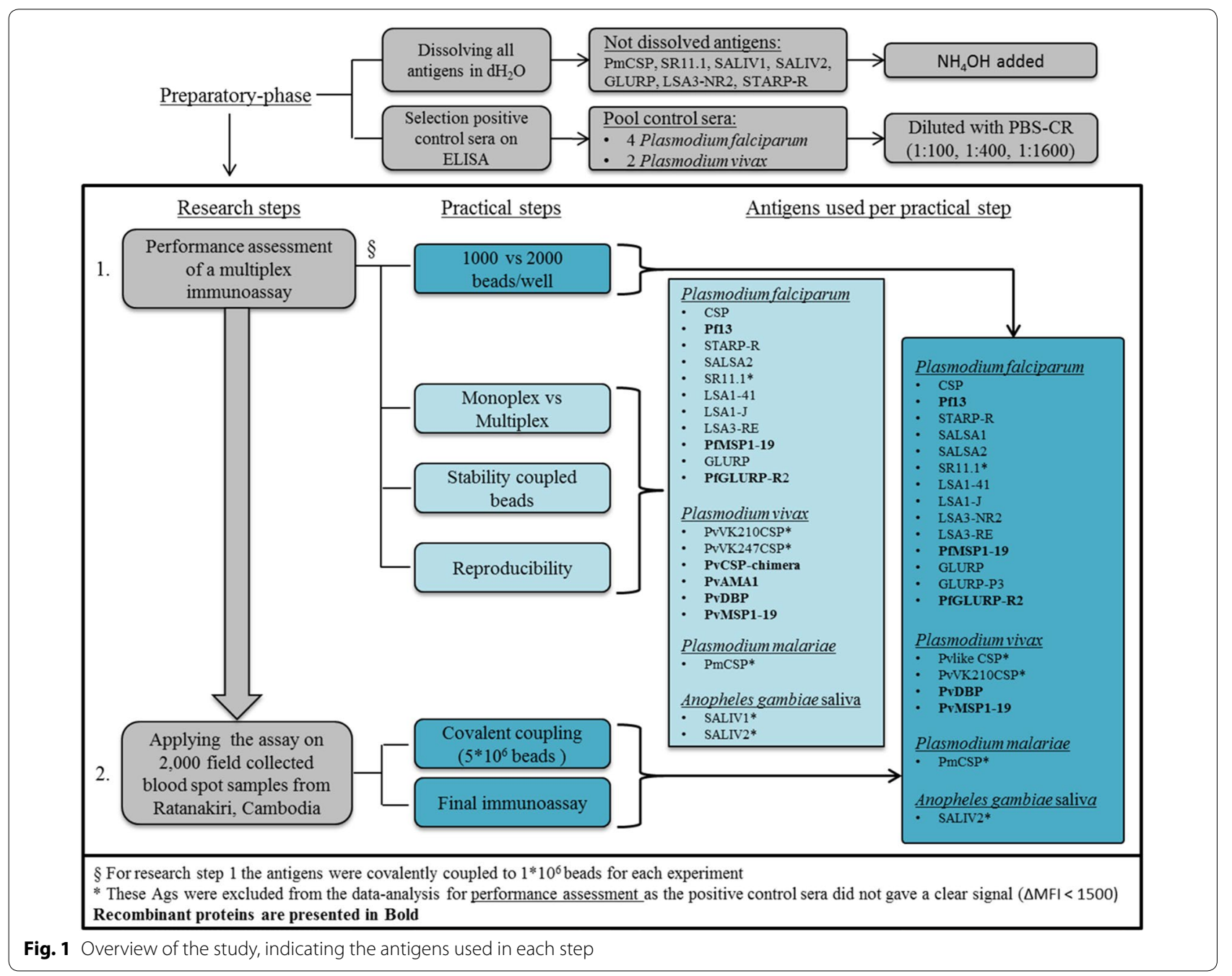

concentration of 2000 and 1000 beads/Ag/well). For the monoplex assay the microsphere working mixture consisted of only one beadset with a coupled Ag, whereas it consisted of a pool of all coupled beadsets for the multiplex assay. In a 96-well plate $25 \mu \mathrm{l}$ of the microsphere working mixture (at 40 beads $/ \mu \mathrm{l}$ ) was added per well and $50 \mu \mathrm{l}$ of serum sample (1:200 dilution) [24]. Plates were incubated at room temperature in the dark for $1 \mathrm{~h}$ on a plate shaker $(600 \mathrm{rpm})$. Plates were washed three times, and $100 \mu \mathrm{l} /$ well of secondary antibody (R-phycoerythrin ${ }^{+}$-conjugated AffiniPure $\mathrm{F}\left(\mathrm{ab}^{\prime}\right)_{2}$ fragment of goat anti-human IgG, Jackson Immuno Research Laboratories) at a dilution of 1:500 was added [24]. Plates were incubated for $30 \mathrm{~min}$ in the dark at room temperature, and washed three times. Beads were resuspended in $100 \mu \mathrm{l}$ of $5 \%$ PBS-BSA, pH 7.4, and read by the MAGPIX $^{\circledR}$ system. A minimum of 400 beads per spectral address were analysed and results were expressed as the median fluorescence intensity (MFI) $[5,25,26]$.

\section{Experiments to assess the performance of the multiplex immunoassay}

For performance assessment, two bead concentrations of 1000 and 2000 beads/Ag/well were compared. The assays performed in monoplex (each Ag separately) and multiplex (all Ags pooled) were compared. Both assays were carried out in triplicate on the positive control pool dilutions $(1: 100,1: 400,1: 1600)$ as previously described $[5$, 25].

Stability of the Ag coupled beads was assessed by performing a multiplex assay directly after coupling the beads and after storage at $4{ }^{\circ} \mathrm{C}$ during two, three, four, eight, and 16 weeks.

Reproducibility of the beads coupling was tested by coupling all Ags at three different time points, followed by an immunoassay on positive control pool dilutions (inter-coupling variability) [17]. Inter- and intraplate reproducibility of the immunoassay was assessed by performing the assay on the positive control pool dilutions 
on three different plates at different time points in 1 day. This was carried out on three different days (interplate variability) and in each plate the positive control pool dilutions were analysed in six-fold (intraplate variability) [27]. In addition, the inter- and intraplate variability was assessed by looking at the positive control pool samples added to each plate with the field blood samples.

\section{Analysis of field samples}

The immunoassay was applied on 2000 field blood samples. Therefore, the microsphere working mixture was prepared at a final concentration of 1000 beads/Ag/ well. All field blood spots were analysed in duplicate on separate plates. In each plate, the positive control pool dilutions (1:100, 1:400, 1:1600), negative control serum (1:200) and blanco (PBS-CR) were analysed in duplicate. In total, 50 plates were analysed and read by the MAGPIX $^{\circledR}$ system.

\section{Data analysis}

All data were incorporated and analysed with $\mathrm{R}$ software package version 3.1.0. [28]. Results were corrected for background signal by subtracting the signal obtained with BSA-coupled beads $\left(\mathrm{MFI}_{\mathrm{BSA}}\right)$ to the median value of the Ag-coupled beads $\left(\mathrm{MFI}_{\mathrm{Ag}}\right)$, defined by: $\Delta \mathrm{MFI}=\mathrm{MFI}_{\mathrm{Ag}}-\mathrm{MFI}_{\mathrm{BSA}}$ [25].

\section{Data analysis for performance assessment}

Ags of which the positive control sera did not give a clear signal $(\Delta \mathrm{MFI}<1500)$ were excluded from the dataanalysis for performance assessment. Non-parametric Spearman's rank correlation tests were used to analyse the relation between the $\Delta$ MFIs for comparing 2000 vs 1000 beads/Ag/well, as well as the monoplex versus the multiplex assay. Correlations were considered significant at $\mathrm{p}<0.05$. Segmented regression models were used for assessing the stability of the beads over time ( $\mathrm{R}$ package 'segmented' [28]). First the breakpoint per Ag and per dilution was estimated, followed by choosing the best linear model through ANOVA tests. Ags showing similar breakpoints in time were grouped and the segmented regression model was rerun on the grouped Ags, taking into account the Ags and dilutions as factor. Mean, standard deviation (SD) and relative standard deviation $\left[\operatorname{RSD}\left(\frac{S D}{\text { Mean }} \times 100 \%\right)\right]$ expressed as a percentage of the mean were calculated from the $\triangle$ MFI for assessing the reproducibility of the assay.

\section{Quality control of the multiplex assay when applied on field blood samples}

To assure the validity of the plates for screening the field blood samples, a quality control was performed on the $\Delta$ MFI values of the high positive control pool samples and on the percentage positivity (PP) calculated from the low positive control pool samples. Results were plotted in Levey Jenning Charts (see Additional file 1) and plates with samples that fell out of $-2 \mathrm{SD}$ and $+2 \mathrm{SD}$ were rejected and repeated. After quality control, $\triangle M F I$ values of each sample and its duplicate were normalized for each Ag using the value of the high positive control (which was in the linear range of the assay). For this purpose, $\Delta \mathrm{MFI}$ was converted to $\mathrm{PP}\left(\frac{\Delta \text { MFIsamples }(\mathrm{Ag} 1)}{\Delta \text { MFI High positive control(Ag1) }} \times 100 \%\right)$ and then the mean PP of the two duplicate samples was calculated. For each sample, the result was rejected when the RSD (relative standard deviation) of two duplicate results exceeded $30 \%$. The results of a total of 1931 samples were accepted for further analysis.

\section{Estimation of the force of infection per antigen}

To estimate the seroprevalence per Ag, a cut-off value per Ag was generated by fitting a normal mixture model on the transformed data using the natural logarithm of $(\mathrm{PP}+1)[4]$. The mean of the negative distribution +3SD was defined as threshold for seropositivity [4]. These dichotomized serological results were used to fit a simple reversible catalytic conversion model based on maximum likelihood. This model estimates one seroconversion rate $(\mathrm{SCR}, \lambda)$ that represents the force of infection and one seroreversion rate (SRR, $\rho$ ) per Ag for all individuals $[4,7$, 9], expressed per person per year. Next, a model estimating two SCRs and one fixed SRR varying across different age groups was fitted. The breakpoint in age was selected using V-fold cross-validation (VFCV) [10]. VFCV randomly partitioned the data into a validation- and training-set. The cross-validation process was repeated five (V) times on the training set and at least once on the validation set. All V results were averaged to one single value (breakpoint). Partitioning the data avoids overfitting [10, 29]. Both models were compared through the likelihood ratio test (LRT) at $\mathrm{p}<0.05[10,30]$.

\section{Ethical clearance}

The study protocol was reviewed and approved by the Cambodian National Ethics Committee on Health Research (Approval $265 \mathrm{NECHR}$ ), the Institutional Review Board of the Institute of Tropical Medicine Antwerp (Approval IRB/AB/ac/154) and the Ethics Committee of the University of Antwerp (Approval B300201112714). Gatekeepers provided informed written consent for the participation of their village. The survey participant or his/her parents or guardian provided informed written consent for individual participation.

\section{Results}

No clear $\triangle$ MFI signal was found for the positive control sera for Ags SR11.1, PvlikeCSP, PvVK210CSP, 
PvVK247CSP, PmCSP, SALIV1 and SALIV2 $(\triangle \mathrm{MFI}<1,500)$. These antigens were therefore excluded from further analysis in the performance assessment (Fig. 1).

\section{Performance assessment of the multiplex immunoassay using 1000 performs as good as 2000 beads/Ag/well}

The $\Delta$ MFIs obtained from the assays using 1000 and 2000 beads/Ag/well were significantly correlated (Spearman's Rank correlation $\mathrm{p}<0.05 ; \mathrm{R}^{2}=0.972$; Fig. 2a). For most Ags, a slightly higher $\Delta$ MFI was observed when using 1000 beads/Ag/well as compared to 2000 beads/ $\mathrm{Ag} /$ well (Additional files 2, 3), and this for all dilutions of the positive control pool (1:100, 1:400 and 1:1600).

\section{Multiplexing beads does not affect the assay results}

Similar $\triangle$ MFI-signals were obtained in monoplex and multiplex (Additional files 2,3), with a clear correlation for all Ags between the $\Delta$ MFIs obtained by the monoplex and the multiplex assays $\left(R^{2}=0.972 ; p<0.05\right.$; Fig. $\left.2 b\right)$.

\section{Stability of the coupled beads depends on the antigens used}

Segmented regression models distinguished three groups of Ags, each with a similar $\triangle$ MFI trend over time (Fig. 3). For these three groups, different breakpoints (i.e., points in time at which the trend in $\triangle$ MFI changes) were observed at 3, 6 and 7 weeks after coupling. For the Ags with lower $\triangle$ MFI values (CSP, Pf13, STARP-R, SALSA2, PvCSP, PvAMA1, and PvDBP) an earlier break in trend is observed, but with a low $\triangle$ MFI decay over time after the breakpoint (Fig. 3; Additional file 4). In general, for all Ags except for PvCSP, the decay in $\triangle$ MFI after 8 weeks was less than $10 \%$ (Additional file 4). As such, the coupled beads can be used for at least 8 weeks after coupling.

\section{The immunoassay is reproducible}

Intercoupling, intraplate and interplate reproducibility was assessed per Ag by evaluating the RSD values (Fig. 4). The $\triangle$ MFI results were divided into three different groups $(<5000 ; 5000 ; \leq 15,000 ;>15,000)$. Highest RSD values were observed for the lowest $\Delta$ MFI values $(<5000)$. In general, the upper limits of the interquartile ranges were lower than $15 \%$ [inter-coupling $11.9 \%$ (8.5-15.2\%), interplate $7.9 \%(6.1-12.4 \%)$, intraplate $5.7 \%(3.0-12.7 \%)]$ which indicates an acceptable reproducibility [27]. The intraplate and interplate variability was also assessed by analysing the RSD on the $\triangle$ MFI of the high, medium and low positive control pool dilutions used as a quality control on the 50 plates with field blood samples (Fig. 5). A low variability was observed for the intraplate reproducibility [RSD $2.7 \%$ (IQR: 1.2-5.1\%)]. The interplate variability was higher than experimentally determined during the performance assessment [RSD $18.6 \%$ (IQR: 16.5-20.1 \%)], but still acceptable.
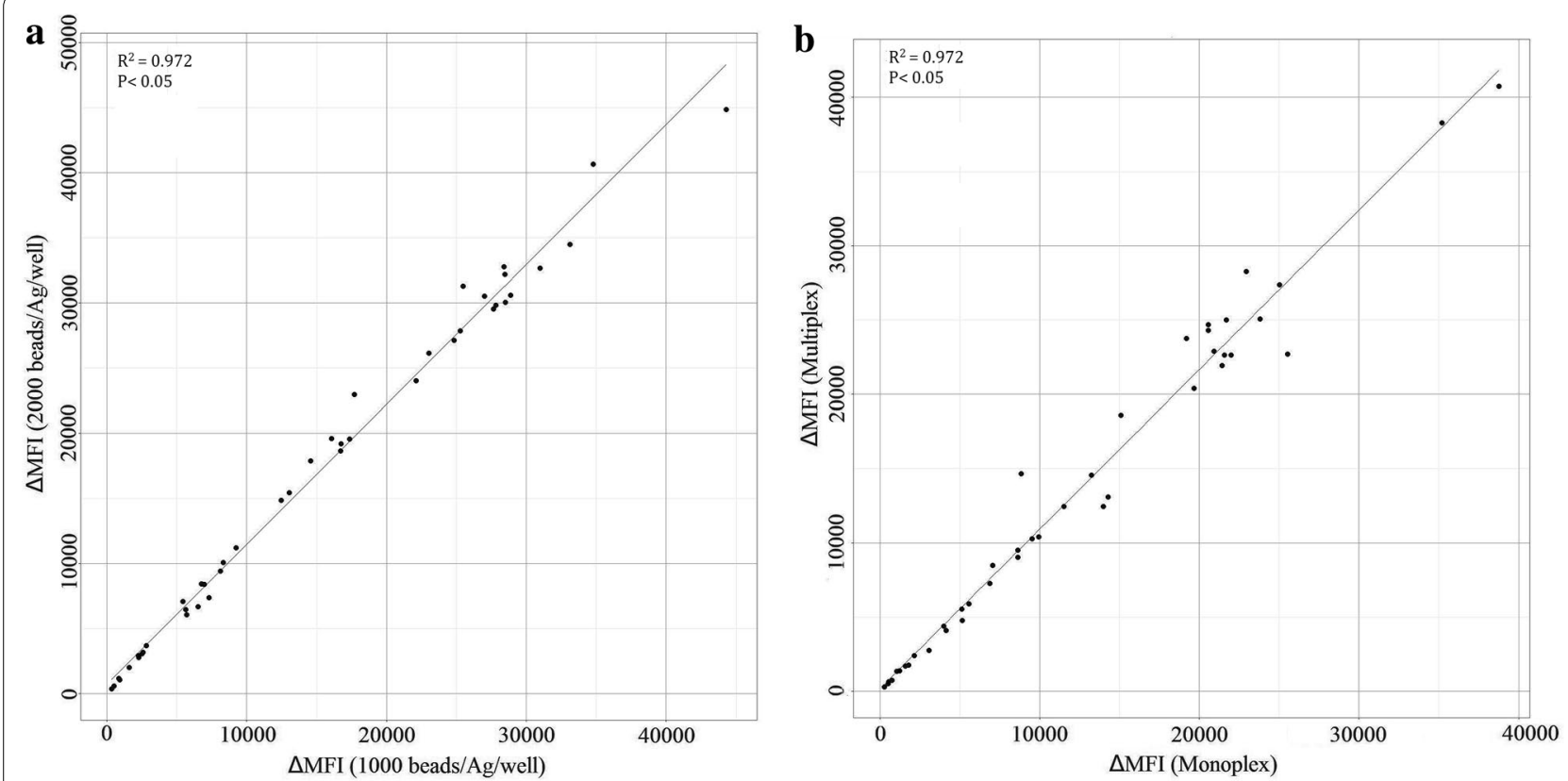

Fig. 2 Correlation between the $\Delta M F I$ values obtained from analysing the positive control pool with the bead-based assay a using 1000 and 2000 beads/Ag/well, and $\mathbf{b}$ in the monoplex and multiplex format 

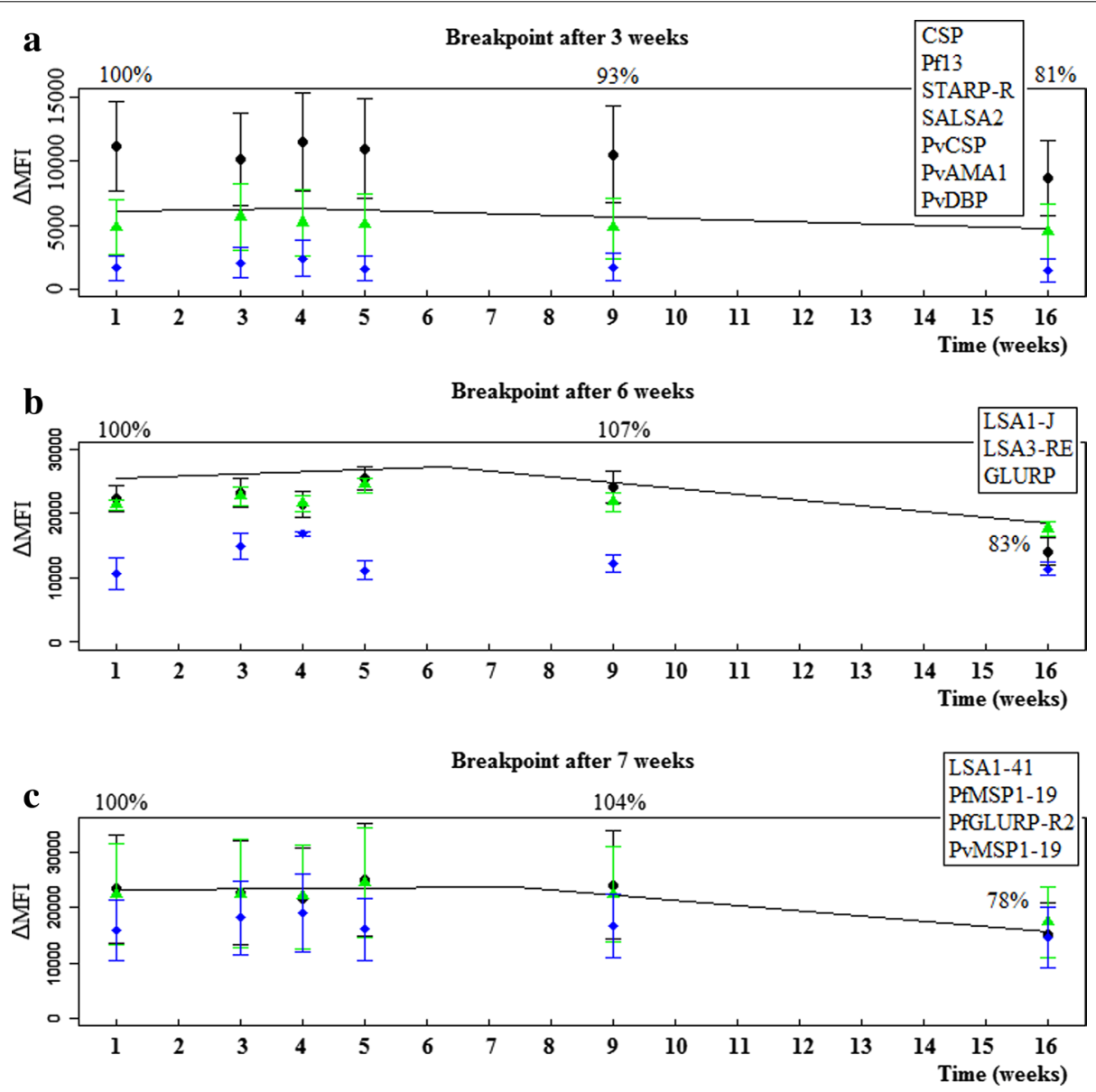

Fig. 3 The stability of the coupled beads as determined by segmented regression analysis taking into account antigens and dilutions as factor. Beads were tested at different time points after coupling and the breakpoints in time were estimated by segmented regression analysis. The trend in $\triangle M F I$ shows different breakpoints for three groups of antigens, namely a 3 weeks after coupling (CSP, Pf13, STARP-R, SALSA2, PVCSP, PvAMA1, and PVDBP), b 6 weeks after coupling (LSA1-J, LSA3-RE, GLURP) and $\mathbf{c} 7$ weeks after coupling (LSA1-41, PfMSP1-19, PfGLURP-R2, and PVMSP1-19)

\section{Application of the assay on blood samples collected in Ratanakiri \\ Quality control of the high positive control serum}

A total of 2000 field blood samples were analysed in duplicate in a total of 5096 -well plates. These plates were validated based on the Levey Jenning Charts of the $\triangle \mathrm{MFI}$ of the high positive controls and the PP of the low positive controls (Additional file 1). The stability of the $\Delta \mathrm{MFI}$ signal of the positive control pool over the analysis of the plates was confirmed by segmented regression, as no breakpoint could be found for the Ags. Based on the duplicate results of the field blood samples, the results of 1931 blood samples were validated for further analysis.

\section{Estimating age-group specific seroconversion rates per antigen}

After dichotomizing the serological results for all blood samples based on a cut-off value, age-seroprevalence curves were constructed and reversible catalytic conversion models allowing one and two SCRs were fitted to the data (Fig. 6; Additional file 5). The force of malaria infection between age groups was shown for 6 out of 20 Ags (CSP, SALSA2, LSA3-RE, PfGLURP-R2, PvVK210CSP, and PmCSP), with the time of change obtained through $\mathrm{V}$-fold cross-validated plots (Additional file 6) ranging between 10 and 20 years. Higher SCRs were observed for the higher age groups for these Ags. When comparing the SCRs and SRRs between serological markers used (Fig. 7), large differences were observed among serological markers used for different life stages of the same parasite, as well as for different parasites. Within the population, highest annual SCRs were modelled for Ags LSA3-RE (0.085 per person per year) and PfMSP119 (0.076 per person per year) and lowest annual SCRs for Ags SALSA1, SR11.1, PvlikeCSP, STARP-R, and PvVK210CSP (ranging from 0.007 to 0.009 per person 

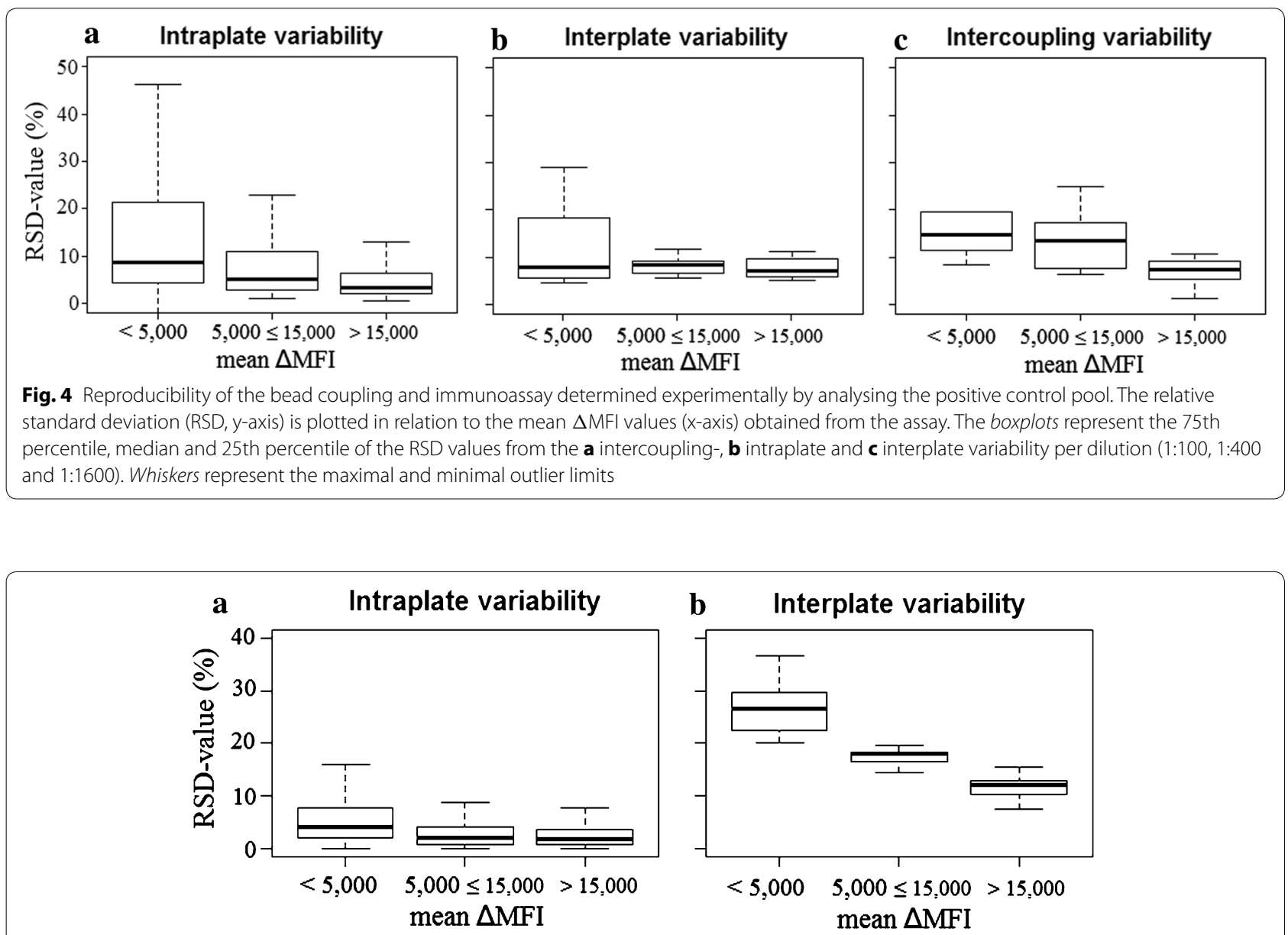

Fig. 5 Reproducibility of the immunoassay based on the quality control samples in the immunoassay applied on field collected samples. The relative standard deviation (RSD, $y$-axis) is plotted in relation to the mean $\Delta \mathrm{MFI}$ values ( $\mathrm{x}$-axis) obtained from the assay. The boxplots represent the 75 th percentile, median and 25th percentile of the RSD values from the intercoupling, intraplate and interplate variability per dilution (1:100, 1:400 and 1:1600). Whiskers represent the maximal and minimal outlier limits

per year). Highest annual SRRs were modelled for Ags LSA3-NR2 (0.128 per person per year) and SALIV 2 (0.083 per person per year), and lowest for Ags LSA3-RE, PfGLURP-R2, GLURP, SR11.1, PvVK210CSP, and PmCSP (ranging from 0.002 to 0.005 per person per year).

\section{Discussion}

This is the first implemented multiplex assay for malaria serology in Southeast Asia. Moreover, with the use of 20 specific Ags against different Plasmodium parasites (Table 1), this assay is the most extensive multiplex assay published on malaria serology, besides Helb et al. [32]. In contrast to most studies, the Abs that can be detected are not only directed against one or two different Plasmodium parasites [5, 10, 17, 24, 25, 33], but responses against $P$. falciparum, $P$. vivax, $P$. malariae, and An. gambiae are simultaneously detected. This is important in malaria elimination programmes, and especially in Southeast Asia where all four human malaria parasites as well as Plasmodium knowlesi are co-occurring [34]. Unfortunately at this stage, Ags specific for Plasmodium ovale and $P$. knowlesi were not available and thus not included in the assay. As the final aim of the study was to analyse 2000 field blood samples, the stability of the coated beads over time and the reproducibility of the assay were first thoroughly assessed and proved to be satisfactory.

Previously it has been shown that multiplex-based serological studies are useful for detecting anti-Plasmodium Abs [5, 10, 15, 17, 18, 24, 25] as well as Abs against other pathogens [31,35-38]. Also in the present study, the technique was shown to be reliable and fast in detecting several serological markers at once. All samples were analysed in less than 8 weeks of time, and more recently, 

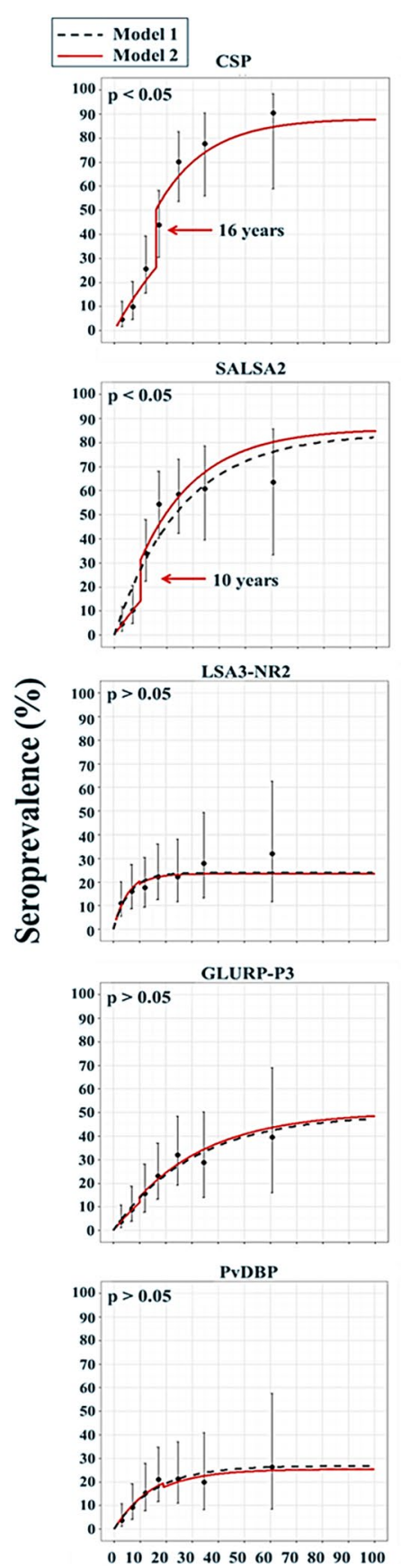

0102030405060708090100
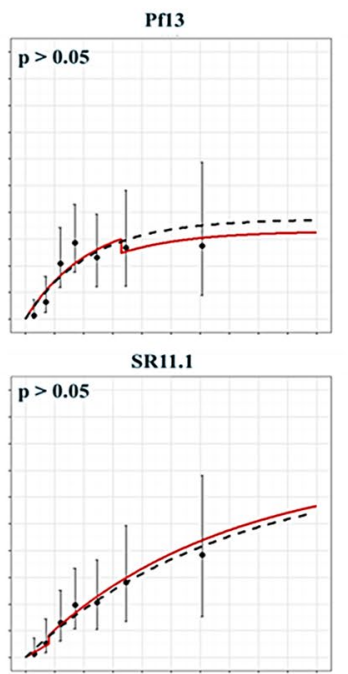

LSA3-RE

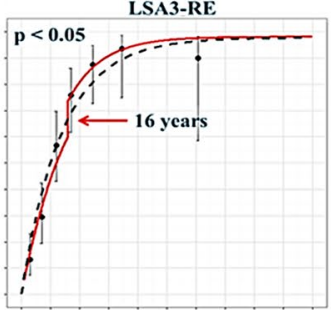

PfGLURP-R2

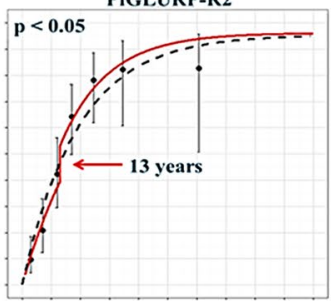

PyMSP1-19

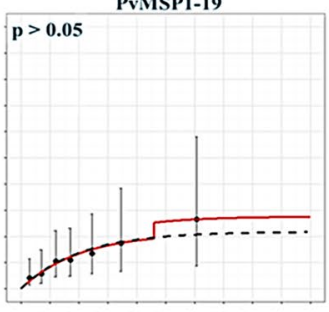

$\begin{array}{lllllllllll}0 & 10 & 20 & 30 & 40 & 50 & 60 & 70 & 80 & 90 & 100\end{array}$
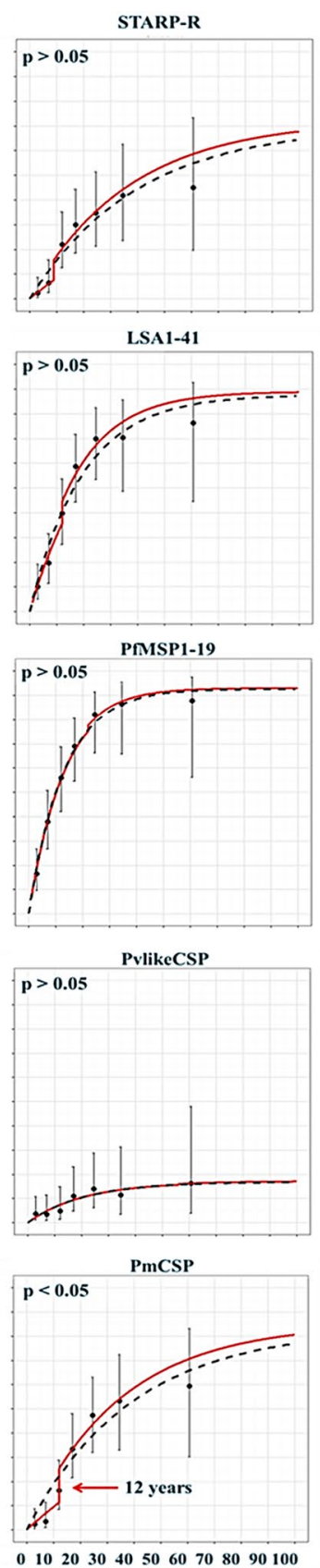

Age (years)
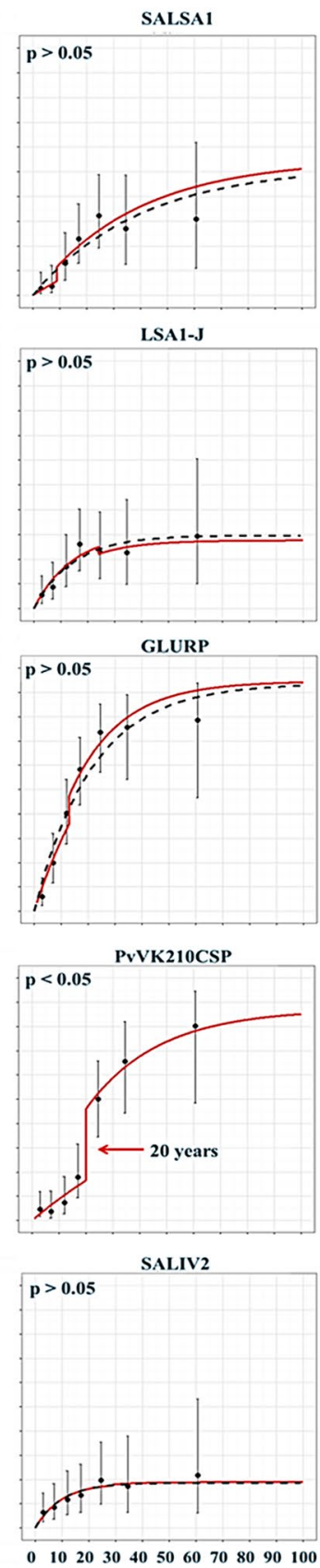

Fig. 6 Age-seroprevalence curves for all antigens analysed by the multiplex assay. Reversible catalytic conversion models allowing one (dashed black line, Model 1) and two (red solid line, Model 2) seroconversion rates were fitted to the data. For six Ags the model allowing two SCRs fitted better as compared to one SCR

over 8000 samples were analysed in duplicate in the same timeframe, showing the possibility to upscale the sample throughput. However, complexity, high investment costs in purchasing a Luminex Analyzer and need for special training, prevent widespread use as compared to ELISA $[5,6]$. A major restriction of this study is the use of the pool of control serum, as this has to be the same during the entire study, adequate quantities should therefore be 


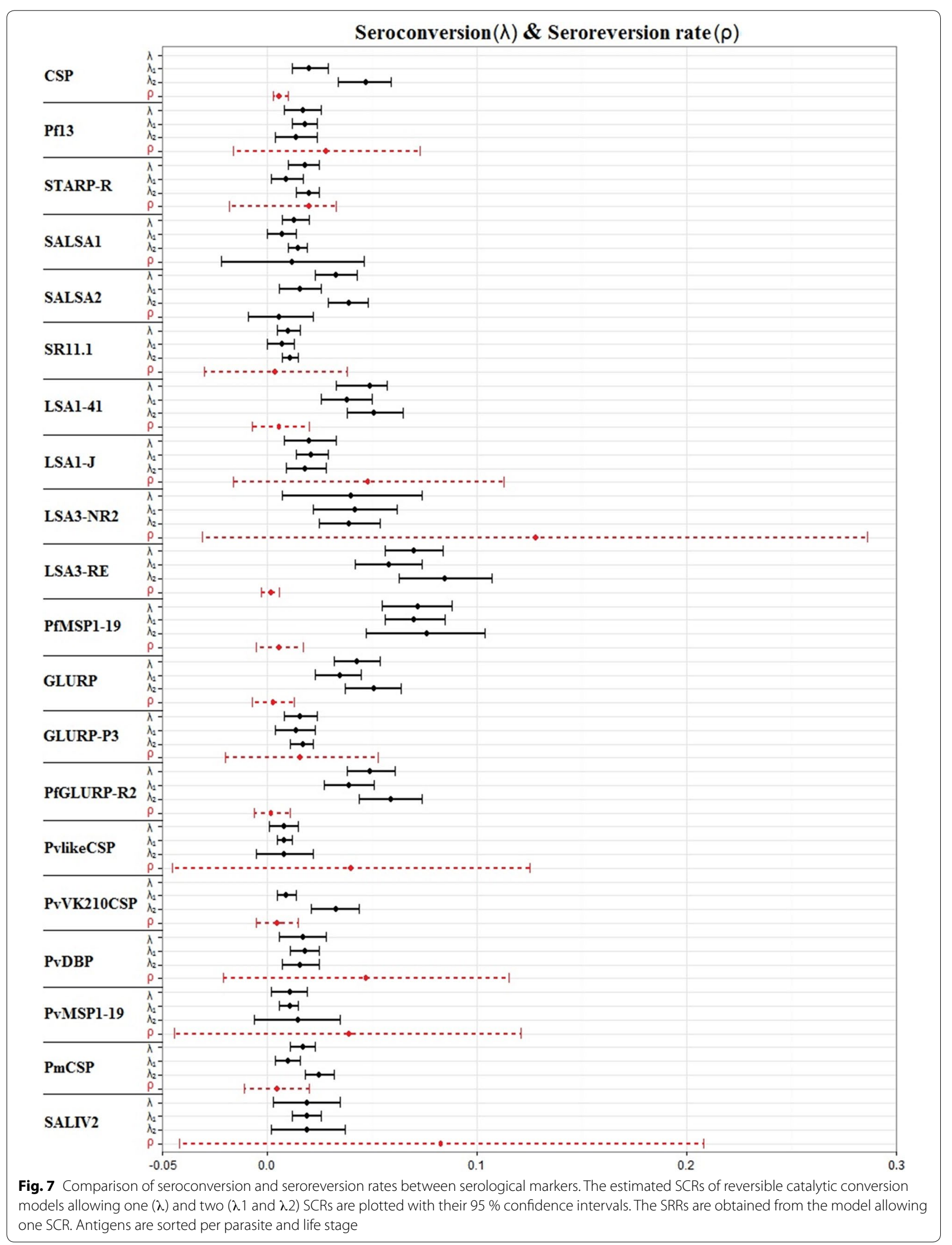


prepared and stored in advance. In previous studies, satisfactory evidence has been presented on the validation of bead-based in comparison to ELISA [5, 39], and this was, therefore, not further explored in the present study.

Several features were considered to assess the performance of the assay. In accordance to previous observations [17], this study confirmed that a reduction of the beads to 1000 beads/Ag/well leads to similar results as compared to the amount of beads recommended by the standard protocols for Luminex-based multiplex immunoassays (2000 or 5000 beads/Ag/well). A rough cost estimation indicates that the use of 1000 instead of 2000 beads/Ag/well reduces the assay costs by one-third. Moreover, the results of previous studies $[5,15,17]$ in which monoplex assays resulted in highly comparable $\Delta$ MFI values as multiplex assays were confirmed. This refutes the concern on cross-reactivity between the different Ag-coupled beads or blocking of Ab responses [15].

The obtained results of the performance assessment revealed that most of the coated beads were stable for up to 2 months, except for Ag PvCSP. This is important as screening approximately 2000 blood spot samples in duplicate took about 7 weeks from the first coupling until the last immunoassay (based on the results 1143 samples can be analysed per week). This stability is lower compared to previous studies, stating that beads are stable for up to 3 or 7 months [5,33], except for Ag STARP-R which was previously shown to be stable for only 1 month [5].

Good reproducibility is an important aspect of an assay as it guarantees that results obtained with the assay performed on different plates and at different time points are comparable to each other. In the experimental set-up used in this study, there is no big difference in reproducibility between and within different plates as shown by similar RSDs. This is in line with other studies that showed accurate and repeatable results according to the interplate, intraplate [5, 15, 27, 31], and intercoupling [40] reproducibility of multiplex assays. In this study, the reproducibility was also assessed by looking at the results obtained from the positive control pool dilutions analysed in duplicate on each of the plates used for screening 2000 blood samples from Ratanakiri Province (total of 50 plates). A much smaller intraplate variability (RSD $<3 \%$ ) was observed compared to the experimental set-up, which was probably due to the fact that samples were only tested in duplicate instead of six times in the experimental set-up. A higher interplate variability was observed, which was still acceptable (RSD <25\%) [27], and most probably due to the use of only two positive controls per plate.

In the present assay the use of peptides and recombinant proteins was combined. Fourteen Plasmodiumspecific peptides (CSP, STARP-R, SALSA1, SALSA2,
SR11.1, LSA1-41, LSA1-J, LSA3-NR2, LSA3-RE, GLURP, GLURP-P3, PvlikeCSP, PvVK210CSP, and PmCSP), one peptide specific for the An. gambiae saliva protein (SALIV2), and five Plasmodium-specific recombinant proteins (Pf13, PfMSP1-19, PfGLURP-R2, PvDBP, and PvMSP1-19) were included in the immunoassay.

After assessment of its performance, the multiplex assay was applied to blood spot samples collected in Ratanakiri Province in Cambodia to detect $\mathrm{Ab}$ responses against 20 different Ags. The seroconversion rate (SCR) was then estimated per Ag by constructing age-seroprevalence curves based on a threshold approach. This is currently the most frequently used way of analysing serological data in malaria epidemiology [4, 7], but which until the present was not applied to data from multiplex assays. By fitting models allowing two SCRs [10], age groups exhibiting similar SCRs can be defined. For six out of 20 Ags (CSP, SALSA2, LSA3-RE, PfGLURP-R2, PvVK210CSP, and PmCSP), the models allowing two SCRs fitted better, and a higher SCR was observed in the older age group. This observation corroborates results obtained in previous studies in Cambodia using GLURP and MSP1-19 as serological markers [9]. A lower SCR in the younger age groups may indicate a lower malaria exposure in the age group. This can be attributed to reductions in malaria transmission over time because of intensified malaria control interventions in the last years, or to different risk behaviour linked to the age groups [9]. Moreover, another explanation would be that children might lose their malaria-specific Abs faster [9]. Indeed, previous studies on malaria serology have shown that $\mathrm{Ab}$ responses in adults fluctuate to a lesser extent than in children $[41,42]$. The statistical model fit used to obtain the estimates for the serological parameters was constrained to have two constant (i.e. age-independent) SCRs and one constant sero-reversion rate (SRR). More elaborate model fitting incorporating age-dependent SCRs and SRRs fell outside the scope of this study.

Until the present very limited information was available on the half-life of the Ab responses to the Ags used and on the individual variation in those responses. This is crucial for interpreting the results obtained with this assay. Serological markers with a long half-life can be used for assessing past exposure, while a short half-life will be useful for assessing recent or even present exposure. The present study has obtained information on the Ab halflife estimated from the SRR as modelled in the reverse catalytic model [43]. Based on this information, fluctuations in Ab half-life were observed per Ag, but all of them seem to have a relatively long half-life (ranging from 5 to $>100$ years). Most studies assume a fixed SRR independent of age and transmission rate [30]. A study based on one Ag (PfMSP1-19) [10] compared longitudinal and 
cross-sectional data (children ages $\leq 11$ years), showing a high concordance of SCRs between both study designs, while large discrepancies were seen between the SRRs. A follow-up study based on a selected combination of Ags (10 out of 655) that compared Ab-responses at individual and population level also shows reliable rates of exposure [32]. The present study is based on cross-sectional sampling and the obtained SRRs are probably not reliable. More extensive analysis on the half-life of these Ab responses is planned by using sequentially collected blood samples from the same individuals, as well as by exploring which of the $\mathrm{Ab}$ responses can best capture the fluctuations in malaria prevalence and incidence observed over time. SCR estimates based on a single serological marker can give a good indication of the force of infection [4, 7]. However, combining the signal from multiple markers representing different life-stages of the parasite in an individual could help reducing individually heterogeneous responses to one particular marker, thereby providing more accurate estimation of the force of infection. A recent follow-up study conducted on a cohort of children demonstrated that measuring Ab-responses to a selection of few Ags provide an accurate estimate of exposure for individuals and communities [32]. Therefore, further data analysis performed with multivariate analysis should provide added value. Moreover, presently it is not possible to exploit the full potential of the assay to take into account individual variation in $\mathrm{Ab}$ responses, as analysis of the SCR is still carried out Ag by Ag. Data analysis methods to combine $\mathrm{Ab}$ responses for estimation of SCRs exist [44] and are currently being extended in the context of this multiplex assay for detection of anti-Plasmodium Abs.

\section{Conclusion}

As many countries engage in malaria elimination it is crucial to improve the understanding of the effectiveness of additional malaria control tools and to be able to identify malaria hotspots for targeted and effective interventions in countries in an advanced elimination phase. With the current malariometric and entomological tools it is challenging to determine the malaria transmission rate in areas where prevalence of infection and incidence is decreasing. The multiplex assay measuring serological markers for malaria transmission was successfully implemented as the first in the Southeast Asian context. Moreover, it proved to be a reliable, fast and useful method for simultaneous detection of Abs against Plasmodium Ags of three different Plasmodium parasites, which has never been done before. The assay was used to screen almost 2000 field blood spot samples in duplicate and proved to be very time efficient and informative. It was also possible to estimate differences in the force of malaria infection, by looking at the differences in SCR over time between the different Ags. For a better estimation of changes in the force of infection on long-term as well as short-term in areas with low malaria endemicity, more information on the longevity of the $\mathrm{Ab}$ responses is needed. The simultaneous detection of several Ags of different parasites offers an opportunity to look for a potential serological marker of very recent malaria transmission, which is the next step of this research. This will prove to be key knowledge for malaria elimination.

\section{Additional files}

\begin{abstract}
Additional file 1: Example of Levey Jenning Charts plotted for the quality control of the immunoassay used for screening the field bloodspot samples. Data analysis started with a quality control on the $\Delta \mathrm{MFI}$-values of the $100 \%$ positive control pool samples (A). The dots represent each positive control sera sample in duplicate per plate. If these dots fell out of the -2SD and +2SD (red area), these plates were rejected and re-analysed. The same quality control was also performed on the PP calculated from the $50 \%$ positive control pool samples per $\mathrm{Ag}$ (B). Based on the outcome of both graphs, plates were accepted or rejected and reanalysed.
\end{abstract}

Additional file 2: Comparison of the $\Delta M F I$ signals obtained from the immunoassay using $\mathbf{1 0 0 0}$ and $\mathbf{2 0 0 0}$ beads/Ag/well. The positive control pool was tested in the multiplex assay (dilutions 1:100, 1:400 and 1:1600) for 1000 beads/Ag/well (dark blue bars) and 2000 beads/Ag/well (light blue bars). The error bars represent upper and lower limits of the 95 $\%$ confidence intervals.

Additional file 3: Comparison of the $\Delta \mathrm{MFI}$ signals obtained from the monoplex and multiplex immunoassay. Each $\mathrm{Ag}$ was tested in monoplex (each Ag separately) and in multiplex (all Ags pooled together) assay on the positive control pool (dilutions 1:100, 1:400 and 1:1600). The error bars represent upper and lower limits of the $95 \%$ confidence intervals.

Additional file 4: Results of the segmented regression analysis for assessing the stability of the antigen coupled beads per antigen. The breakpoints were estimated with the R-package 'segmented' and the $\Delta \mathrm{MFI}$-values obtained at Week (Wk) 4, Wk 8 and Wk16 were converted into percentages compared to the $\Delta \mathrm{MFI}$ value obtained directly after coupling (WkO).

Additional file 5: Seroconversion $(\boldsymbol{\lambda})$ and seroreversion $(\rho)$ rates estimated for each antigen by catalytic regression models allowing one (Model 1) and two (Model 2) seroconversion rates.

Additional file 6: V-fold cross-validated plots with age-varying seroconversion rates. These plots were used to estimate the optimal breakpoint in age per antigen. The VFCV randomly partionate the data into a validation set and a training set. Then the cross-validation is repeated $V$-times on the training set and a least once on the validation set. All $V$-results are avaraged and gave a single estimation.

\section{Authors' contributions}

Sample collection of the survey was performed by the CNM team (National Centre for Parasitology, Entomology and Malaria Control), the ITM Antwerp team and the Institut Pasteur du Cambodge team in Ratanakiri Province in Cambodia. The study design and literature research has been performed at the ITM by KK, LD and MC. Protocols were written by KK, based on protocols from Institut Pasteur de Madagascar (IVW), verified by LC and validated by DM. Laboratorial work for the performance of the assay was performed by KK and LC, and KK executed the screening of the blood spot samples. Selection of the pool of control sera and the high positive control dilutions was done by KK, LD and LC. Data entry and analysis of the results were performed at the ITM by KK, and verified by LD, VS and MC. The first draft of the manuscript was written by KK. All authors read and approved the final manuscript. 


\section{Author details}

${ }^{1}$ Department of Biomedical Sciences, Institute of Tropical Medicine, Antwerp, Belgium. ${ }^{2}$ Department of Biomedical Sciences, University of Antwerp, Antwerp, Belgium. ${ }^{3}$ Molecular Epidemiology Unit, Institut Pasteur du Cambodge, Phnom Penh, Cambodia. ${ }^{4}$ National Centre for Parasitology, Entomology and Malaria Control, Phnom Penh, Cambodia. ${ }^{5}$ Infectious Diseases Immunology, Institut Pasteur de Madagascar, Antananarivo, Madagascar. ${ }^{6}$ Department of Biology, University of Antwerp, Antwerp, Belgium.

\section{Acknowledgements}

We would like to thank all colleagues at the ITM and IPC for all their support and contributions to fulfil this manuscript. We are extremely grateful that Odile Mercereau-Puijalon provided us recombinant proteins Pf13 and PvDBP. We would like to thank Chris Drakeley for providing recombinant proteins PvMSP1-19 and PfMSP1-19 and Takafumi Tsuboi for providing recombinant proteins PVAMA1 and PvCSP-chimera. Furthermore, we would like to thank Prof Alfredo Mayor for the valuable discussions about this topic. This work is part of a larger project on the evaluation of large use of tropical repellent in addition to insecticide treated nets in control malaria transmission. This work was funded by the Bill and Melinda Gates Foundation under the Global Health Grant number OPP1032354. KK was supported by the VLIRUOS and the association of Les Amis des Instituts Pasteur à Bruxelles.

\section{Compliance with ethical guidelines}

\section{Competing interests}

The authors declare that they have no competing interests.

Received: 16 March 2015 Accepted: 24 August 2015

Published online: 04 September 2015

\section{References}

1. WHO. World malaria report 2013. Geneva: World Health Organization; 2013.

2. Bousema T, Stevenson J, Baidjoe A, Stresman G, Griffin JT, Kleinschmidt I, et al. The impact of hotspot-targeted interventions on malaria transmission: study protocol for a cluster-randomized controlled trial. Trials. 2013;14:36.

3. Cook J, Reid H, lavro J, Kuwahata M, Taleo G, Clements A, et al. Using serological measures to monitor changes in malaria transmission in Vanuatu. Malar J. 2010;9:169.

4. Drakeley CJ, Corran PH, Coleman PG, Tongren JE, McDonald SLR, Carneiro $\mathrm{I}$, et al. Estimating medium- and long-term trends in malaria transmission by using serological markers of malaria exposure. Proc Natl Acad Sci USA. 2005;102:5108-13.

5. Ambrosino E, Dumoulin C, Orlandi-Pradines E, Remoue F, Toure-Baldé A, Tall A, et al. A multiplex assay for the simultaneous detection of antibodies against 15 Plasmodium falciparum and Anopheles gambiae saliva antigens. Malar J. 2010;9:317.

6. Tangpukdee N, Duangdee C, Wilairatana P, Krudsood S. Malaria diagnosis: a brief review. Korean J Parasitol. 2009;47:93-102.

7. Corran P, Coleman P, Riley E, Drakeley C. Serology: a robust indicator of malaria transmission intensity? Trends Parasitol. 2007;23:575-82.

8. Drakeley C, Cook J. Potential contribution of sero-epidemiological analysis for monitoring malaria control and elimination: historical and current perspectives. Adv Parasitol. 2009;69:299-352.

9. Cook J, Speybroeck N, Sochanta T, Somony H, Sokny M, Claes F, et al. Sero-epidemiological evaluation of changes in Plasmodium falciparum and Plasmodium vivax transmission patterns over the rainy season in Cambodia. Malar J. 2012;11:86.

10. Arnold BF, Priest JW, Hamlin KL, Moss DM, Colford JM, Lammie PJ. Serological measures of malaria transmission in Haiti: comparison of longitudinal and cross-sectional methods. PLoS One. 2014;9:e93684.

11. Von Fricken ME, Weppelmann TA, Lam B, Eaton WT, Schick L, Masse R, et al. Age-specific malaria seroprevalence rates: a cross-sectional analysis of malaria transmission in the Ouest and Sud-Est departments of Haiti. Malar J. 2014;13:361.
12. Noor AM, Mohamed MB, Mugyenyi CK, Osman MA, Guessod HH, Kabaria $\mathrm{CW}$, et al. Establishing the extent of malaria transmission and challenges facing pre-elimination in the Republic of Djibouti. BMC Infect Dis. 2011:11:121.

13. Voller A. Fluorescent antibody methods and their use in malaria research. Bull World Health Organ. 1964;30:343-54.

14. She RC, Rawlins ML, Mohl R, Perkins SL, Hill HR, Litwin CM. Comparison of immunofluorescence antibody testing and two enzyme immunoassays in the serologic diagnosis of malaria. J Travel Med. 2007;14:105-11.

15. Fouda GG, Leke RFG, Long C, Druilhe P, Zhou A, Taylor DW, et al. Multiplex assay for simultaneous measurement of antibodies to multiple Plasmodium falciparum antigens. Clin Vaccine Immunol. 2006;13:1307-13.

16. Fernandez-Becerra C, Sanz S, Brucet M, Stanisic DI, Alves FP, Camargo $E P$, et al. Naturally-acquired humoral immune responses against the $\mathrm{N}$ - and C-termini of the Plasmodium vivax MSP1 protein in endemic regions of Brazil and Papua New Guinea using a multiplex assay. Malar J. 2010:9:29.

17. Ondigo BN, Park GS, Gose SO, Ho BM, Ochola LA, Ayodo GO, et al. Standardization and validation of a cytometric bead assay to assess antibodies to multiple Plasmodium falciparum recombinant antigens. Malar J. 2012;11:427.

18. Lammie PJ, Moss DM, Brook Goodhew E, Hamlin K, Krolewiecki A, West SK, et al. Development of a new platform for neglected tropical disease surveillance. Int J Parasitol. 2012;42:797-800.

19. Sluydts V, Heng S, Coosemans M, Van Roey K, Gryseels C, Canier L, et al. Spatial clustering and risk factors of malaria infections in Ratanakiri Province, Cambodia. Malar J. 2014;13:387.

20. Canier L, Khim N, Kim S, Sluydts V, Heng S, Dourng D, et al. An innovative tool for moving malaria PCR detection of parasite reservoir into the field. Malar J. 2013;12:405.

21. Luminex Corporation. XMAP Antibody Coupling Kit User Manual. http:// www.luminexcorp.com/Products/ReagentsMicrospheres/xMAPAntibodyCouplingKit/. 2011.

22. Corporation Luminex. Description and operation of the luminex technology. Austin: Texas, USA; 2012. p. 20.

23. Luminex Corporation. Fundamental assay techniques protein training (CN-0164-01). http://www.cvent.com/events/luminex-learningcustomer-education-event/eventsummary-2476c07b727540f6a1c1bdb34e400694.aspx. 2012.

24. Khaireh BA, Briolant S, Pascual A, Mokrane M, Machault V, Travaillé C, et al. Plasmodium vivax and Plasmodium falciparum infections in the Republic of Djibouti: evaluation of their prevalence and potential determinants. Malar J. 2012;11:395

25. Sarr JB, Orlandi-Pradines E, Fortin S, Sow C, Cornelie S, Rogerie F, et al. Assessment of exposure to Plasmodium falciparum transmission in a low endemicity area by using multiplex fluorescent microsphere-based serological assays. Parasit Vectors. 2011;4:212.

26. Luminex Corporation. xMap technology. http://www.luminexcorp.com/ TechnologiesScience/XMAPTechnology/\#. 2012.

27. Van Gageldonk PGM, van Schaijk FG, van der Klis FR, Berbers GAM. Development and validation of a multiplex immunoassay for the simultaneous determination of serum antibodies to Bordetella pertussis, diphtheria and tetanus. J Immunol Methods. 2008;335:79-89.

28. R Core Team. R: a language and environment for statistical computing. R Foundation for statistical computing. Vienna, Austria. 2014. http:// www.R-project.org/

29. Dudoit S, Van Der Laan MJ. Asymptotics of cross-validated risk estimation in estimator selection and performance assessment. Stat Methodol. 2005:2:131-54.

30. Stewart L, Gosling R, Griffin J, Gesase S, Campo J, Hashim R, et al. Rapid assessment of malaria transmission using age-specific sero-conversion rates. PLoS One. 2009;4:e6083.

31. Ferbas J, Thomas J, Hodgson J, Gaur A, Casadevall N, Swanson SJ. Feasibility of a multiplex flow cytometric bead immunoassay for detection of anti-epoetin alfa antibodies. Clin Vaccine Immunol. 2007;14:1165-72.

32. Helb DA, Tetteh KKA, Felgner PL, Skinner J, Hubbard A, Arinaitwe E, et al. Novel serologic biomarkers provide accurate estimates of recent Plasmodium falciparum exposure for individuals and communities. Proc Natl Acad Sci USA. 2015;112:4438-47. 
33. Cham GKK, Kurtis J, Lusingu J, Theander TG, Jensen ATR, Turner L. A semiautomated multiplex high-throughput assay for measuring lgG antibodies against Plasmodium falciparum erythrocyte membrane protein 1 (PfEMP1) domains in small volumes of plasma. Malar J. 2008;7:108.

34. Khim N, Siv S, Kim S, Mueller T, Fleischmann E, Singh B, et al. Plasmodium knowlesi Infection in Humans, Cambodia, 2007-2010. Emerg Infect Dis. 1900;2011:17

35. Binnicker MJ, Jespersen DJ, Harring JA, Rollins LO, Beito EM. Evaluation of a multiplex flow immunoassay for detection of epstein-barr virus-specific antibodies. Clin Vaccine Immunol. 2008;15:1410-3.

36. Drummond JE, Shaw EE, Antonello JM, Green T, Page GJ, Motley CO, et al. Design and optimization of a multiplex anti-influenza peptide immunoassay. J Immunol Methods. 2008;334:11-20.

37. Whelan C, Shuralev E, O'Keeffe G, Hyland P, Kwok HF, Snoddy P, et al. Multiplex immunoassay for serological diagnosis of Mycobacterium bovis infection in cattle. Clin Vaccine Immunol. 2008;15:1834-8.

38. Michel A, Waterboer T, Kist M, Pawlita M. Helicobacter pylori multiplex serology. Helicobacter. 2009;14:525-35.

39. Elshal MF, McCoy JP. Multiplex bead array assays: performance evaluation and comparison of sensitivity to ELISA. Methods. 2006;38:317-23.

40. Ondigo BN, Hodges JS, Ireland KF, Magak NG, Lanar DE, Dutta S, et al. Estimation of recent and long-term malaria transmission in a population by antibody testing to multiple Plasmodium falciparum antigens. J Infect Dis. 2014;210:1123-32.

41. Scholzen A, Sauerwein RW. How malaria modulates memory: activation and dysregulation of B cells in Plasmodium infection. Trends Parasitol. 2013:29:252-62.

42. Taylor RR, Egan A, McGuinness D, Jepson A, Adair R, Drakely C, et al. Selective recognition of malaria antigens by human serum antibodies is not genetically determined but demonstrates some features of clonal imprinting. Int Immunol. 1996;8:905-15.

43. Muench H Jr. Catalytic Models in Epidemiology. 1st ed. Cambridge: Harvard University Press; 1959.

44. Hens N, Shkedy Z, Aerts M, Faes C, Van Damme P, Beutels P. Modeling infectious disease parameters based on serological and social contact data. New York, Heidelberg, Dordrecht, London: Springer; 2012.

45. Sutherland CJ. Surface antigens of Plasmodium falciparum gametocytes - a new class of transmission-blocking vaccine targets? Mol Biochem Parasitol. 2009;166:93-8.

46. Vigan-Womas I, Guillotte M, Juillerat A, Vallieres C, Lewit-Bentley A, Tall $A$, et al. Allelic diversity of the Plasmodium falciparum erythrocyte membrane protein 1 entails variant-specific red cell surface epitopes. PLoS One. 2011;6:e16544.
47. Greenwood BM, Bojang K, Whitty CJM, Targett GAT. Malaria. Lancet. 2005;365:1487-98.

48. Fidock A, Gras-Masse H, Lepers J, Brahimi K, Benmohamed L, Mellouk S, et al. Liver stage antigen-1 is well conserved and contains potent $B$ and $T$ cell determinants. J Immunol. 1994;153:190-204.

49. Theisen M, Vuust J, Gottschau A, Jepsen S, Høgh B. Antigenicity and immunogenicity of recombinant glutamate-rich protein of Plasmodium falciparum expressed in Escherichia coli. Clin Diagn Lab Immunol. 1995:2:30-4.

50. Theisen M, Soe S, Jessing SG, Meng L, Oeuvray C, Druilhe P, Jepsen S. Identification of a major B-cell epitope of the Plasmodium falciparum glutamate-rich protein (GLURP), targeted by human antibodies mediating parasite killing. Vaccine. 2001;19:204-12.

51. Henry-Halldin CN, Sepe D, Susapu M, McNamara DT, Bockarie M, King $\mathrm{CL}$, et al. High-throughput molecular diagnosis of circumsporozoite variants VK210 and VK247 detects complex Plasmodium vivax infections in malaria endemic populations in Papua New Guinea. Infect Genet Evol. 2011;11:391-8

52. Cheng Y, Ito D, Sattabongkot J, Lim CS, Kong DH, Ha KS, et al. Serological responses to a soluble recombinant chimeric Plasmodium vivax circumsporozoite protein in VK210 and VK247 population. Malar J. 2013;12:323.

53. Triglia T, Healer J, Caruana SR, Hodder AN, Anders RF, Crabb BS, et al. Apical membrane antigen 1 plays a central role in erythrocyte invasion by Plasmodium species. Mol Microbiol. 2000;38:706-18.

54. Yildiz Zeyrek F, Palacpac N, Yuksel F, Yagi M, Honjo K, Fujita Y, et al. Serologic markers in relation to parasite exposure history help to estimate transmission dynamics of Plasmodium vivax. PLoS One. 2011;6:e28126.

55. Menard D, Chan ER, Benedet C, Ratsimbasoa A, Kim S, Chim P, et al. Whole genome sequencing of field isolates reveals a common duplication of the Duffy binding protein gene in Malagasy Plasmodium vivax strains. PLoS Negl Trop Dis. 2013;7:e2489.

56. Poinsignon A, Cornelie S, Mestres-Simon M, Lanfrancotti A, Rossignol $\mathrm{M}$, Boulanger $\mathrm{D}$, et al. Novel peptide marker corresponding to salivary protein gSG6 potentially identifies exposure to Anopheles bites. PLoS One. 2008;3:e2472.

\section{Submit your next manuscript to BioMed Central and take full advantage of:}

- Convenient online submission

- Thorough peer review

- No space constraints or color figure charges

- Immediate publication on acceptance

- Inclusion in PubMed, CAS, Scopus and Google Scholar

- Research which is freely available for redistribution

Submit your manuscript at

www.biomedcentral.com/submit

C Biomed Central 